NOVA

University of Newcastle Research Online

nova.newcastle.edu.au

Kouretzis, George P.; Andrianopoulos, Konstantinos I.; Sloan, Scott W.; Carter, John P. "Analysis of circular tunnels due to seismic P-wave propagation, with emphasis on unreinforced concrete liners" Computers and Geotechnics Vol. 55, p. 187-194 (2014)

Available from: http://dx.doi.org/10.1016/j.compgeo.2013.08.012

Accessed from: http://hdl.handle.net/1959.13/1056712 


\title{
Analysis of circular tunnels due to seismic P-wave propagation, with emphasis on unreinforced concrete liners
}

\author{
George P. Kouretzis ${ }^{1 *}$, Konstantinos I. Andrianopoulos ${ }^{2}$, Scott W. Sloan ${ }^{1}$ and John P. \\ Carter $^{1}$ \\ ${ }^{1}$ ARC Centre of Excellence for Geotechnical Science and Engineering, Faculty of Engineering and \\ Built Environment, The University of Newcastle, Callaghan, NSW 2308, Australia \\ ${ }^{2}$ School of Science and Technology, Hellenic Open University, Parodos Aristotelous 18, GR 26335, \\ Patra, Greece
}

\begin{abstract}
A set of closed-form expressions to calculate tunnel liner forces due to compressional seismic P-wave propagation is presented. The results are compared against a state-of-practice method that considers only shear S-waves, and verified against dynamic numerical analyses. Under the realistic assumption of full-slip conditions at the liner-rock mass interface, it is shown that P-waves can lead to significantly higher axial hoop forces compared to S-waves, and can be critical for tunnels bored through areas of irregular topography/geological stratigraphy. The findings are of particular interest for the analysis of unreinforced concrete tunnel liners, where earthquake effects can be a governing factor.
\end{abstract}

Keywords: earthquakes; tunnels; unreinforced concrete; P- waves

\footnotetext{
*Corresponding author - email: Georgios.Kouretzis@newcastle.edu.au tel. +61 24921 6449, postal address: EA Building, University of Newcastle, Callaghan NSW 2308, Australia
} 


\section{Introduction}

The need to reduce infrastructure costs has led to the adoption of unreinforced concrete for the construction of final tunnel lining sections, at least for tunnel sections bored through a competent rock mass where long-term external loads are expected to be generally low in occurrence and magnitude. Modern guidelines and code provisions, such as the French AFTES [1], the German DIN 1045-1 [2] and Eurocode EN-1992 [3], offer methodologies applicable to the design of unreinforced concrete tunnel liners. These are based on two fundamental design requirements: a) compressive stresses in the liner must remain low compared to the concrete design strength, and b) crack depths must be limited, generally up to $50 \%$ of the crosssection height for high axial force load cases [1]. The latter requirement is quantified by imposing restrictions on the maximum developing eccentricity $e_{\text {lim }}=M_{\max } / T_{\max }$, where $M_{\max }$ is the bending moment in the cross-section and $T_{\max }$ is the axial hoop force.

Unlike conventional reinforced concrete liners, which have been proven to suffer less from earthquakes compared to above-ground structures [4, 5], significant damage to unreinforced tunnel linings has been recorded during the Kobe (1995) and the Niigata-Chuetsu (2004) earthquakes in Japan, which has a long tradition in using unreinforced concrete for tunnel linings $[6,7,8]$. Although the damage distribution in the tunnel networks suggested that unreinforced tunnel linings can indeed survive earthquake effects under certain conditions, transient seismic wave propagation is recognized to be an important load case to be considered during their analysis and design.

\section{Existing closed-form solutions for the calculation of internal forces due to S-wave propagation and limitations of current state-of-practice}

Taking into account rock mass-structure interaction effects, a series of elastic closedform solutions have been proposed for determining the internal forces in the lining of 
a circular tunnel due to the deformation generated by seismic shear or S-wave propagation [e.g. 9, 10,11, 12]. Here we focus on one of the most widely-used ones, proposed by Wang [9] and also discussed by Hashash et al. [13]. The validity of Wang's solution under specific conditions has been verified more recently by Hashash et. al [14], on the basis of independent quasi-static numerical analyses results. Note that Wang's, as well as all other similar elastic solutions, assume infinite tensile bond strength at the liner-rock mass interface.

Wang [9] derived the following expressions for the internal forces in the lining, under the assumption of full-slip conditions, at the liner-rock mass interface:

$$
\begin{aligned}
& T_{\text {max }}= \pm \frac{1}{6} K_{1} \frac{E_{m}}{\left(1+\nu_{m}\right)} r \gamma_{\max } \\
& M_{\max }= \pm \frac{1}{6} K_{1} \frac{E_{m}}{\left(1+\nu_{m}\right)} r^{2} \gamma_{\text {max }}
\end{aligned}
$$

where:

$$
K_{1}=12\left(1-\nu_{m}\right) /\left(2 F+5-6 \nu_{m}\right), \quad F=E_{m}\left(1-\nu_{i}^{2}\right) r^{3} / 6 E_{i} I\left(1+\nu_{m}\right) \text { is the flexibility }
$$

ratio $[15,16], \gamma_{\max }=v_{S} / C_{S}$ is the maximum free-field seismic shear strain due to $\mathrm{S}$ wave propagation, and $C_{S}=\sqrt{G_{m} / \rho_{m}}$ is the shear wave propagation velocity. The sign convention adopted is presented in Figure 1.

Under no-slip conditions at the liner-rock mass interface, the expression providing the maximum axial force is transformed to: 


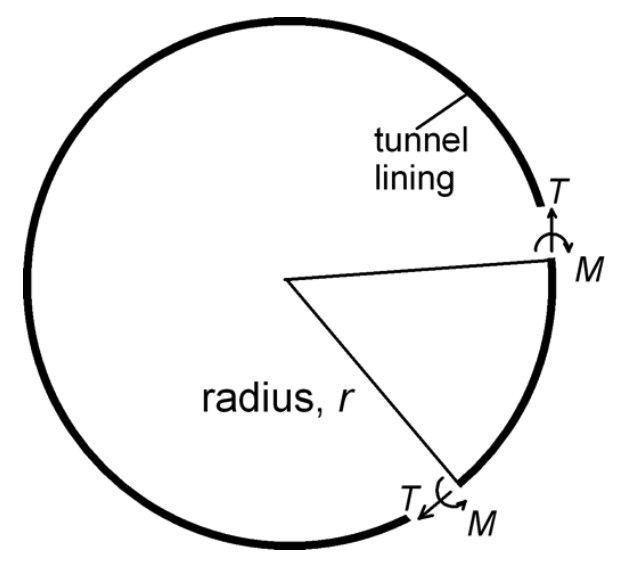

Figure 1. Internal lining forces sign convention.

$$
T_{\max }= \pm K_{2} \frac{E_{m}}{2\left(1+\nu_{m}\right)} r \gamma_{\max }
$$

where:

$K_{2}=1+\frac{F\left(1-2 \nu_{m}\right)(1-C)-\frac{1}{2}\left(1-2 \nu_{m}\right)^{2} C+2}{F\left[\left(3-2 \nu_{m}\right)+\left(1-2 \nu_{m}\right) C\right]+C\left[\frac{5}{2}-8 \nu_{m}+6 \nu_{m}^{2}\right]+6-8 \nu_{m}}$, and $C=E_{m}\left(1-v_{i}^{2}\right) r / E_{i} t\left(1+\nu_{m}\right)\left(1-2 \nu_{m}\right)$ is the compressibility ratio $[15,16]$.

A solution for the calculation of the maximum bending moment under no-slip conditions was not presented by Wang [9], however Hashash et al. [14] recommend that the solution for the full-slip assumption could be used under no-slip conditions as well. Hashash et al. [14] compared other solutions for no-slip conditions [10, 11] against numerical analyses results, and advised against their use, as they resulted in non-conservative estimates of the liner internal forces. Moreover, Hashash et al. [14] suggest that, for most tunnels, the interface condition is between full-slip and no-slip, so that both cases should be checked to calculate the most critical seismic internal forces, as the solution for full-slip conditions results in significantly lower axial forces in the tunnel lining. 
The analytical expressions derived by Wang [9] cover the case of shear or S-wave propagation only, an assumption which is fairly accurate for free-field conditions, i.e., for tunnels in large overburden areas that are bored through homogeneous rock mass conditions, where shear waves transfer the highest portion of seismic energy. Nevertheless, for tunnels bored through areas of irregular topographic relief or variable geotechnical conditions, the effect of secondary compressional P-waves resulting from reflection/refraction of S-waves at the ground surface or at the interface of rock mass layers of different properties, cannot be ignored. Indeed, under these conditions, the assumption of free-field shear wave propagation is no longer valid [e.g., 17, 18, 19, 20].

Furthermore, the expressions proposed by Wang [9] suggest that the maximum tensile axial force acting in the liner due to wave propagation is algebraically equal to the maximum compressive axial force. Thus, when it comes to the analysis of an unreinforced tunnel liner, which cannot sustain pure tension due to the lack of reinforcement, Wang's solution implies that failure will occur whenever the seismic tensile force exceeds the compressive axial force imposed by the self-weight of the concrete (assuming that additional compressive rock mass loads, due to the degradation of the primary support measures, have not developed in the liner). On this issue, Sedarat et al. [21] performed quasi-static numerical analyses to investigate the effects of the contact interface for a circular tunnel subjected to Swave propagation. Among other findings, these authors suggested that proper simulation of the interface properties prevents the development of unrealistic tensile stresses. Note, however, that the work of Sedarat et al. [21] assumes that the tunnel liner bears the full load due to rock mass relaxation during excavation, and thus is inapplicable to unreinforced tunnels constructed with the NATM method; where the primary lining, consisting of shotcrete and rockbolts, is the main load-bearing component. 
In this paper, the following key issues which affect the final design of unreinforced tunnel liners are treated analytically and numerically:

a) The effect of "secondary" P-wave propagation is quantified via the development of closed-form expressions for the axial hoop force and the bending moment in a circular tunnel liner under no-slip and full-slip conditions.

b) Results of the proposed solution for the P-wave case are compared to the results predicted by Wang [9] for the S-wave case. These results are also complemented with those from a new expression for the maximum bending moment under no-slip interface conditions.

c) The effect of assuming an infinite bond strength at the liner-rock mass interface is validated both for the $\mathrm{S}$ - and $\mathrm{P}$-waves cases by means of dynamic numerical analyses. These results provide insight into the development of tensile axial forces in the tunnel lining.

\section{Proposed expressions for the analysis of circular tunnel liners due to P- and S-wave propagation.}

3.1 Internal forces considering P- wave propagation under no-slip and full-slip interface conditions.

A closed-form elasticity solution is proposed to calculate the axial forces and bending moments in an annular tunnel lining, resulting from the deformation imposed by compressional P-wave propagation. The expressions follow from an adaptation of the well-established elasticity solution for rock mass-lining interaction of Ranken et al. $[22,23]$.

The Ranken et al. solution for static loads is based on the following assumptions: a) the rock mass surrounding the tunnel is an infinite, elastic, homogeneous and isotropic medium, b) the tunnel liner is linear elastic, and c) plane-strain symmetry conditions apply. Both cases of full-slip or no-slip are considered for the liner-rock 
mass interface condition. Here we are interested in the part of the solution referring to the liner response in a rock mass subjected to an externally applied pressure (overpressure loading), which implies that the lining is installed before the external loads are applied. This condition of in situ geostatic stresses i.e., a vertical stress equal to $\gamma_{m} \cdot h$ and horizontal stress $K_{o} \cdot \gamma_{m} \cdot h$, is depicted in Figure 2. The internal forces of the tunnel liner depend on the relative stiffness of the liner compared to the rock mass, as the latter is quantified via the flexibility ratio, $F$, and the compressibility ratio, C. The complete solution of Ranken et al. [22] for the geostatic stress field in provided in Appendix A.

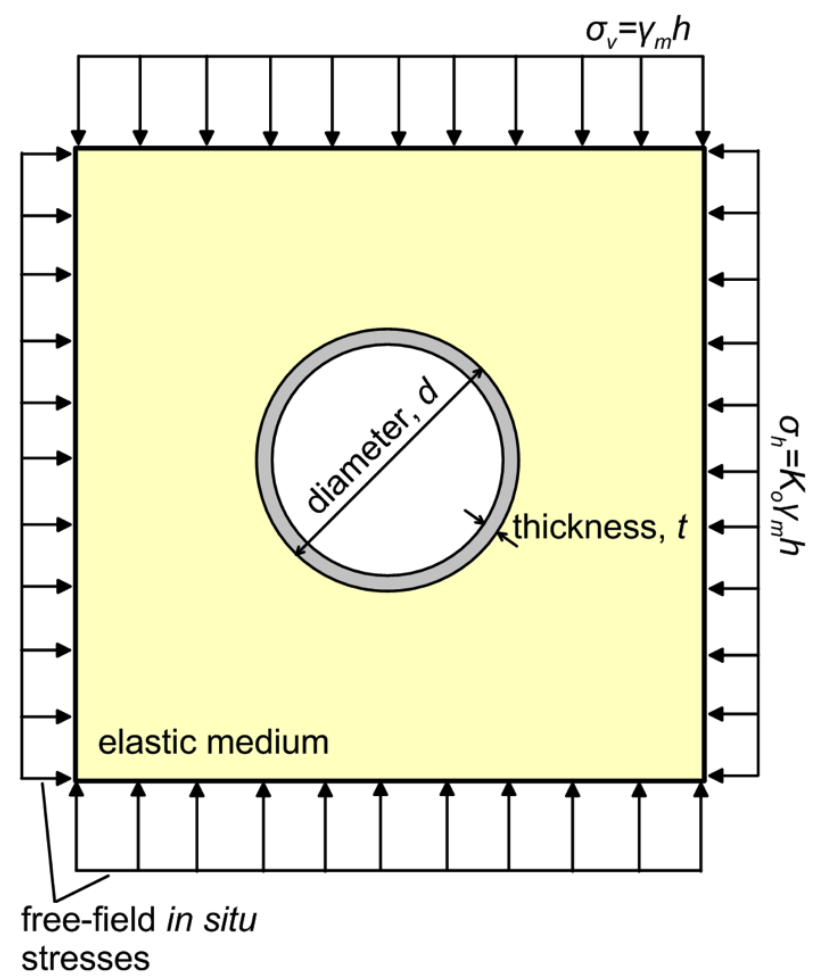

Figure 2. Geostatic stresses and elastic closed-form model of rockmass-lining interaction (adapted after [23]).

Following a similar procedure to the one proposed by Wang [9] for the shear S-wave case, the expressions proposed by Ranken et al. [22] can be transformed to calculate the additional seismic internal forces in the liner due to seismic P-wave propagation with a planar front. This is done by setting the in situ stress ratio to be $K_{o}=0$ and $\gamma_{m} \cdot h= \pm \sigma_{\max }$, where $\sigma_{\max }$ is the maximum free-field normal stress due to the 
P-waves, which is a function of the amplitude of the strong motion and of the elastic properties of the surrounding rock mass:

$$
\sigma_{\max }= \pm v_{p} \sqrt{\rho_{m}\left(K_{m}+\frac{4}{3} G_{m}\right)}= \pm v_{p} \sqrt{\rho_{m} G_{m}} \cdot \sqrt{\frac{2\left(1-\nu_{m}\right)}{\left(1-2 \nu_{m}\right)}}
$$

In the above, the symbol $( \pm)$ accounts for the cyclic nature of the loading while $M_{m}=K_{m}+(4 / 3) G_{m}$ is the constrained modulus of the rock mass.

Table 1. Internal forces of a circular liner due to P- wave propagation, under noslip and full-slip interface conditions.

\begin{tabular}{|l|l|l|}
\hline $\begin{array}{l}\text { Interface } \\
\text { conditions }\end{array}$ & Axial force, $\mathbf{T}_{\max }$ & Bending Moment, $\mathbf{M}_{\max }$ \\
\hline No slip & $\pm\left[K_{3}+K_{4}\right] \cdot \sigma_{\max } \cdot \frac{r}{2}$ & $\pm\left[\frac{C\left(1-2 \nu_{m}\right)}{6 \cdot F} K_{3}+1-\frac{K_{4}}{2}-K_{6}\right] \cdot \sigma_{\max } \cdot \frac{r^{2}}{2}$ \\
\hline Full slip & $\pm\left[K_{3}+K_{5}\right] \cdot \sigma_{\max } \cdot \frac{r}{2}$ & $\left.\pm \frac{C\left(1-2 \nu_{m}\right)}{6 \cdot F} K_{3}+K_{5}\right] \cdot \sigma_{\max } \cdot \frac{r^{2}}{2}$ \\
\hline
\end{tabular}

where:

\begin{tabular}{|l}
$K_{3}=1-\frac{\left(1-2 \nu_{m}\right)(C-1)}{1+\left(1-2 \nu_{m}\right) C}=\frac{2\left(1-\nu_{m}\right)}{1+\left(1-2 \nu_{m}\right) C}$ \\
$K_{4}=1+\frac{\left(1-2 \nu_{m}\right)(1-C) F-0.5\left(1-2 \nu_{m}\right)^{2} C+2}{\left[\left(3-2 \nu_{m}\right)+\left(1-2 \nu_{m}\right) C\right] F+\left[0.5\left(5-6 \nu_{m}\right)\right]\left(1-2 \nu_{m}\right) C+\left(6-8 \nu_{m}\right)}$ \\
$K_{5}=1-\frac{2 F+1-2 \nu_{m}}{2 F+5-6 \nu_{m}}=\frac{2 F+5-6 \nu_{m}-2 F-1+2 \nu_{m}}{2 F+5-6 \nu_{m}}=\frac{4\left(1-\nu_{m}\right)}{2 F+5-6 \nu_{m}}$ \\
$K_{6}=\frac{\left[\left(1+\left(1-2 \nu_{m}\right) C\right] F-\left[0.5\left(1-2 \nu_{m}\right) C\right]-2\right.}{\left[\left(3-2 \nu_{m}\right)+\left(1-2 \nu_{m}\right) C\right] F+\left[0.5\left(5-6 \nu_{m}\right)\right]\left(1-2 \nu_{m}\right) C+\left(6-8 \nu_{m}\right)}$
\end{tabular}

After substituting the above values for $K_{0}$ and $\gamma_{\mathrm{m}} \cdot h$ in the expressions defined in Appendix A, closed-form expressions are derived for the seismic axial hoop force and bending moment in the liner (Table 1), under both full-slip and no-slip liner-rock mass interface conditions. The internal forces are functions of the tunnel radius $r$, the 
compressibility factor $C$, the flexibility factor $F$, and the Poisson's ratio of the surrounding rock mass $v_{\mathrm{m}}$.

Ranken et al. [22] proposed different expressions for the axial force and bending moment at the liner crown and springline (Appendix A). This is appropriate for static load cases (overpressure or relaxation loads), but is invalid for transient wave propagation loading, as the path of the waves is not known a-priori and they can impinge on the tunnel section at a variety of angles. Thus, only the highest internal force value along the cross-section is presented in Table 1 for the seismic load case. Note that the maximum axial force and bending moment develop at the same polar angle in the lining cross-section.

3.2 Liner bending moment considering S-wave propagation under no-slip interface conditions.

To supplement the expressions provided by Wang [9], the additional seismic bending moment due to S-wave propagation under no-slip conditions can be estimated by employing the expressions provided by Ranken et al. [22] and setting $K_{o}=-1$ and $\gamma_{m} \cdot h= \pm T_{\max }$, where $I_{\max }$ is the maximum free-field seismic shear stress:

$$
\tau_{\max }= \pm v_{s} \sqrt{\rho_{m} \cdot G_{m}}
$$

In this way, the maximum bending moment at the tunnel liner can be calculated from Eq. (6) below, with the aid of the factors $K_{4}$ and $K_{6}$ that are presented in Table 1.

$$
M_{\max }= \pm\left[2-K_{4}-2 K_{6}\right] \cdot \tau_{\max } \cdot \frac{r^{2}}{2}
$$

Note that the expressions given by Ranken et al. [22], when used to derive a closedform expression for the axial force unded no-slip conditions, would essentially provide the same result as Eq. (3).

It is emphasised that values of the in situ stress ratio of $K_{o}=0$ and $K_{o}=-1$ are respectively employed in this study to describe the additional rock mass stress field 
resulting from seismic wave $\mathrm{P}$ - and S-wave propagation along a planar front. In particular, $K_{o}=-1$ corresponds to a state of simple shear where $\sigma_{1}=T_{\max }$ and $\sigma_{3}=-T_{\max }$ with $I_{\max }$ being the shear stress induced by planar SV- wave propagation. On the other hand $K_{o}=0$ reflects a uniaxial loading condition, where $\sigma_{1}=\sigma_{\max }$ and $\sigma_{3}=0$, and corresponds to planar P- wave propagation. This concept for describing a uniform seismic stress field was originally proposed by Wang [9] for S-waves, and has been widely adopted by a other researchers including Hashash et al. $[13,14]$ and Sedarat et al. [21]. The validity of this assumption will be verified numerically in the following sections.

3.3 Comparison of liner internal forces for the S- and P-wave propagation case.

Internal liner forces and eccentricity values due to $\mathrm{P}$-wave propagation, calculated from the expressions of Table 1, as well as the liner forces due to S-wave propagation calculated from Eqs (1-3) and Eq. (6), are illustrated in Figure 3. 

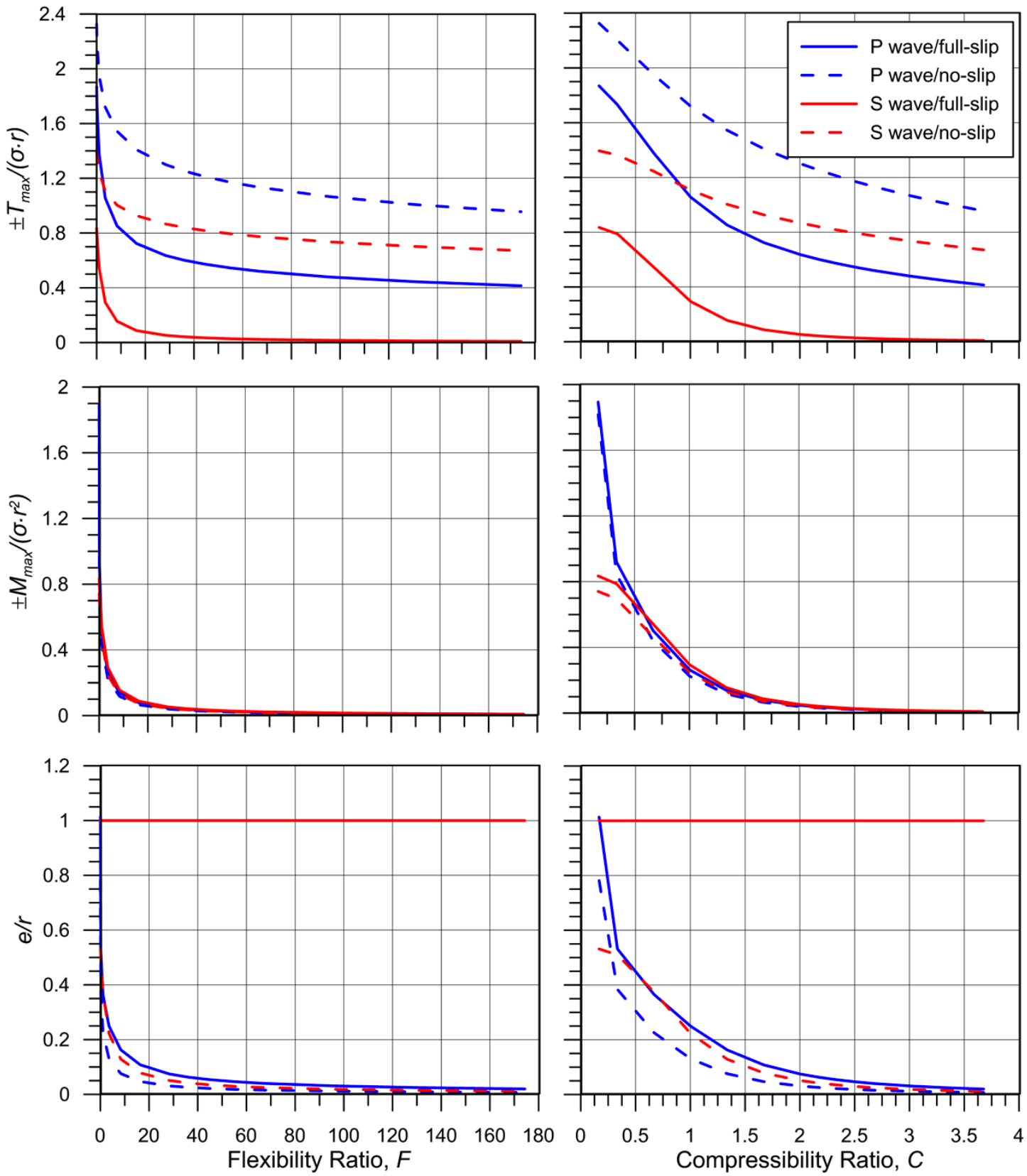

Figure 3. Normalized axial forces, bending moments and eccentricity values, plotted against the flexibility ratio, $F$ and the compressibility ratio, $C$ (Poisson ratio of the rock mass $v_{m}=0.2$ ).

Fourteen (14) different Compressibility Ratio (C) / Flexibility Ratio $(F)$ combinations are considered to create the continuous plots, while the Poisson's ratio of the rock mass is assumed equal to $v_{m}=0.2$. The axial forces and bending moments are normalized as $T_{\max } /(\sigma \cdot r)$ and $M_{\max } /\left(\sigma \cdot r^{2}\right)$ respectively [9], where $\sigma=\sigma_{\max }$ is the maximum normal seismic stress for the P-wave case, or the maximum shear stress 
$\left(\sigma=T_{\max }\right)$ for the S-wave case. Additionaly, the eccentricity $e$ is normalized against the tunnel radius, $r$.

Figure 3 shows that the normalized axial forces due to P-waves are considerably higher than the corresponding forces due to S-waves, both for the no-slip and the full-slip cases, provided the tunnel is relatively flexible compared to the surrounding ground with a flexibility factor $F>20[24,25]$. This will unquestionably be the case for unreinforced tunnel liners constructed in a competent rock mass.

The above finding is based on the assumption that the peak seismic stress due to the "secondary" P-waves is equal to the peak seismic stress due to the S-waves. Since P-waves are generally linked to the vertical component of the seismic motion, one could employ the maximum vertical seismic ground velocity to calculate the internal liner forces due to P-waves; equal to $90 \%$ of the horizontal seismic velocity according to EN-1998-1 [26] for a Type 1 elastic response spectra, corresponding to a surface wave earthquake magnitude, $M_{s}>5.5$. However, this would not alter the essence of the above comparison.

For full-slip conditions, which is a more realistic assumption $[21,27]$ when a smooth waterproofing membrane is installed to protect the tunnel liner, the axial forces due to P-waves are significant; unlike the axial forces due to S-waves which tend to zero for high values of the flexibility factor. This implies that P-waves would govern the design for this case.

On the other hand, the bending moment values for flexible tunnels (and consequently the eccentricities) are generally low, and do not appear sensitive to the wave type or interface conditions. The latter finding confirms the suggestion of Hashash et al. [14] to use the full-slip expression for calculating bending moments in the no-slip interface case, as well as the conclusions of Sedarat et al. [21] for S-waves. 


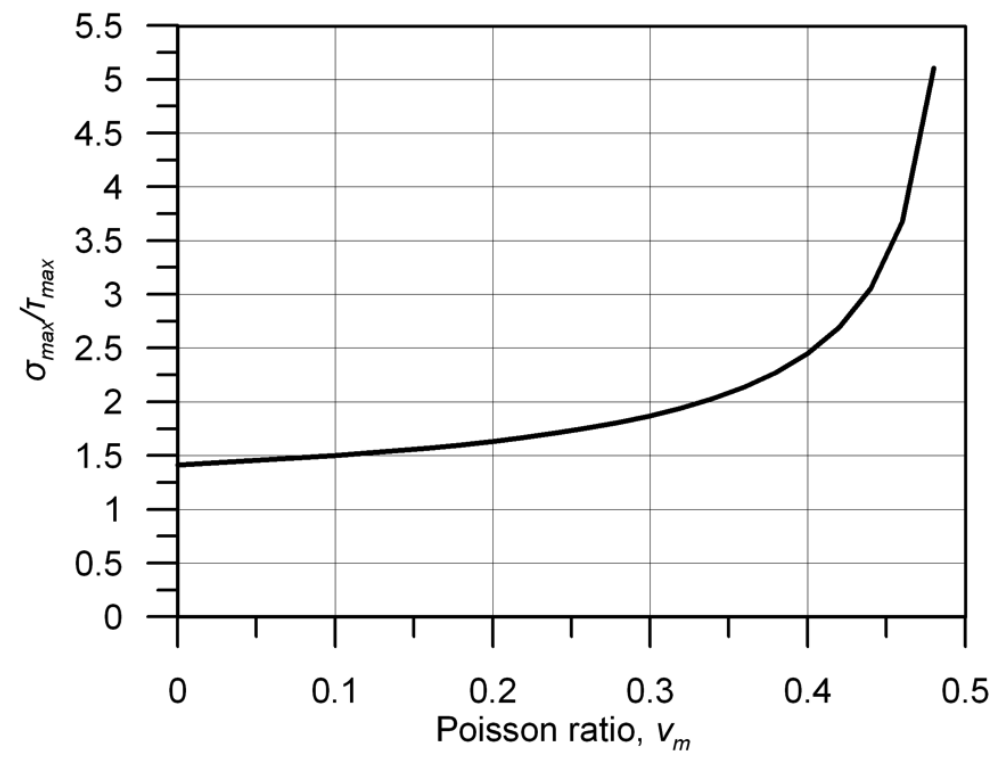

Figure 4. Variation of the $\sigma_{\max } / \tau_{\max }$ ratio with the Poisson's ratio of the rock mass, assuming the same peak seismic velocity for both $\mathrm{P}$ - and $\mathrm{S}$ - waves.

The effect of the Poisson's ratio on the results for P-wave and S-wave loading is shown in Figure 4, where the ratio of the maximum normal seismic stress $\sigma_{\max }$ over the maximum shear stress $I_{\max }$ is plotted against Poisson's ratio (assuming that both the P- and S-waves have the same peak seismic velocity).

One should keep in mind that the above expressions were derived under the assumption that no separation occurs at the rock mass-liner interface under tensile normal stresses. Hence, cyclic harmonic loading will result in an absolute maximum tensile axial force in the tunnel lining that is equal to the maximum compressive seismic axial force, a simplification that is discussed further in the next section.

Results from the analytical expressions are compared against the numerical results of dynamic analyses, considering two surface bond scenarios: (a) no-slip conditions with no separation at the interface, and (b) full-slip conditions with zero normal tensile bond strength. 


\section{Numerical verification and effect of separation at the liner-rock mass interface}

Verification of the expressions derived previously, and an investigation of the fundamental assumption of an infinite tensile bond strength at the liner-rock mass interface, was carried out using a dynamic finite element model which simulates a circular tunnel geometry, harmonic cyclic excitation, and free-field geometry conditions (Figure 5). The input data for the example case study considered are summarized in Table 2.

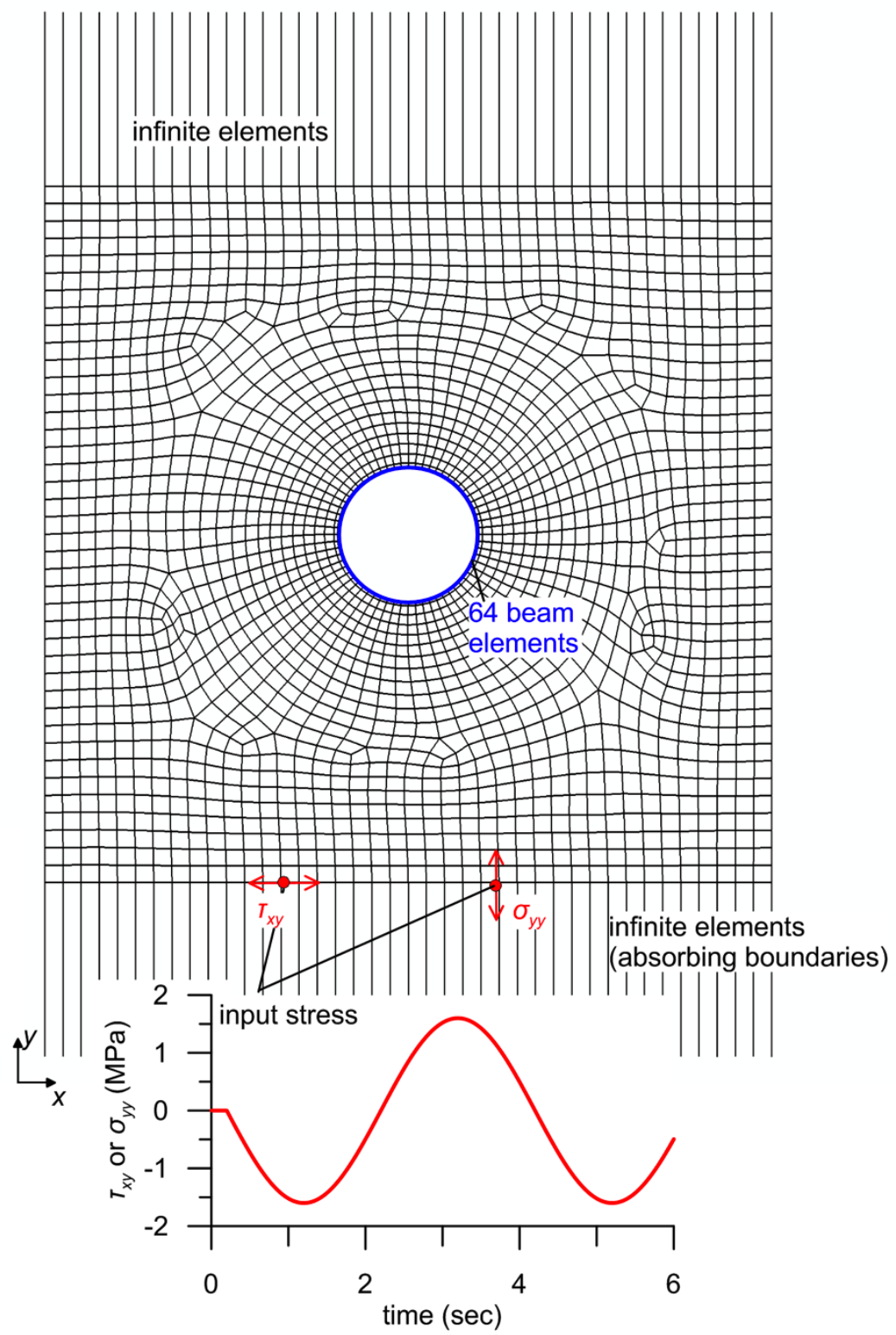

Figure 5. Numerical model of the tunnel liner and surrounding rock mass, employed in the verification of the analytical solutions. 


\begin{tabular}{|l|l|}
\hline Rock mass properties & $2.00 \mathrm{GPa}$ \\
\hline Modulus of elasticity, $E_{m}$ & $1.11 \mathrm{GPa}$ \\
\hline Bulk modulus, $K_{m}$ & $0.83 \mathrm{GPa}$ \\
\hline Shear modulus, $G_{m}$ & $645 \mathrm{~m} / \mathrm{sec}$ \\
\hline Shear wave velocity, $C_{S}$ & $1054 \mathrm{~m} / \mathrm{sec}$ \\
\hline Compressional wave velocity, $C_{P}$ & 0.2 \\
\hline Poisson ratio, $v_{m}$ & $2.0 \mathrm{Mg} / \mathrm{m}^{3}$ \\
\hline density, $\rho_{m}$ & \\
\hline Liner properties & $19 \mathrm{GPa}$ \\
\hline Modulus of elasticity, $E_{l}$ & $4.0 \mathrm{~m}$ \\
\hline Radius, $r$ & 0.2 \\
\hline Poisson ratio, $v_{l}$ & $0.15 \mathrm{~m}$ \\
\hline Thickness, $t$ & 3193 \\
\hline Flexibility ratio, $F$ & 3.74 \\
\hline Compressibility ratio, $C$ & \multicolumn{2}{|l}{} \\
\hline Seismic excitation & $1.60 \mathrm{MPa}$ \\
\hline Peak seismic stress $\left(I_{x y}=2 \rho \cdot C_{S} \cdot V_{S}\right.$ or $\left.\sigma_{y y}=2 \rho \cdot C_{P} \cdot v_{P}\right)$ & $0.620 \mathrm{~m} / \mathrm{sec}$ \\
\hline Peak ground velocity attributed to S- waves, $v_{S}$ & $0.379 \mathrm{~m} / \mathrm{sec}$ \\
\hline Peak ground velocity attributed to P- waves, $v_{P}$ &
\end{tabular}

The finite element code ABAQUS/Standard [28] was employed for the analyses, as it is capable of robust predictions of the contact behaviour in dynamic problems. Elastic 2-D beam elements (type=B21) were adopted to model the tunnel liner, using 64 elements along the perimeter, while 1984 2-D plane-strain continuum elements (type=CPE4) were used to model the surrounding rock. Infinite elements (type=CINPE4), which are implemented in ABAQUS/Standard to function as absorbing boundaries in wave propagation problems, were introduced at the top and bottom boundaries of the model (Figure 5), to avoid wave reflection phenomena. The input sinusoidal motion was applied at the bottom of the $40 \mathrm{~m} \times 40 \mathrm{~m}$ grid as a stresstime history (Table 2), as per common practice, whereas the direction of the input stress varied, depending on the wave type (shear or compressive).

Note that no loads from rock mass relaxation are assumed to be transferred to the final lining, so that all the rock mass loads are borne by the temporary support shell. This assumption is appropriate for an unreinforced tunnel section constructed with 
the NATM method in competent rock mass, where the final lining is installed after the primary lining has reached equilibrium.

Four (4) analyses were performed to model the tunnel response under S- and Pwave propagation both for full-slip and no-slip conditions. Full-slip conditions at the rock mass-structure interface were simulated via the ABAQUS/Standard contact surface model, following the Mohr-Coulomb failure criterion while assuming zero friction and allowing for separation under tensile contact stresses in the beamcontinuum elements interface. Next, no-slip conditions were introduced, where the beam elements representing the liner are tied to the nodes of the surrounding rock mass.

Table 3. Comparison of analytical and numerical maximum axial hoop forces and bending moments, for the example case study considered.

\begin{tabular}{|l|l|l|l|l|}
\hline \multirow{2}{*}{} & \multicolumn{4}{|c|}{ Analytical results } \\
\cline { 2 - 5 } & $\begin{array}{l}\text { S- wave } \\
\text { (full-slip) }\end{array}$ & $\begin{array}{l}\text { S- wave } \\
\text { (no-slip) }\end{array}$ & $\begin{array}{l}\text { P-wave } \\
\text { (full-slip) }\end{array}$ & $\begin{array}{l}\text { P-wave } \\
\text { (no-slip) }\end{array}$ \\
\hline $\boldsymbol{T}_{\max } /(\boldsymbol{\sigma} \cdot \boldsymbol{r})$ & $\pm 0.0005^{\star}$ & $\pm 0.6775^{\star}$ & \pm 0.2528 & \pm 0.5913 \\
\hline $\boldsymbol{M}_{\max } /\left(\boldsymbol{\sigma} \cdot \boldsymbol{r}^{2}\right)$ & $\pm 0.5268^{\star}$ & $\pm 0.4446^{\star *}$ & \pm 0.2934 & \pm 0.2531 \\
\hline & \multicolumn{4}{|c|}{ Numerical results } \\
\cline { 2 - 5 } & $\begin{array}{l}\text { S- wave } \\
\text { (full-slip) }\end{array}$ & $\begin{array}{l}\text { S- wave } \\
\text { (no-slip) }\end{array}$ & $\begin{array}{l}\text { P- wave } \\
\text { (full-slip) }\end{array}$ & $\begin{array}{l}\text { P-wave } \\
\text { (no-slip) }\end{array}$ \\
\hline $\boldsymbol{T}_{\max } /(\boldsymbol{\sigma} \cdot \boldsymbol{r})$ & -0.0019 & \pm 0.6538 & -0.2547 & \pm 0.6183 \\
\hline $\boldsymbol{M}_{\max } /\left(\boldsymbol{\sigma} \cdot \boldsymbol{r}^{2}\right)$ & \pm 0.5264 & \pm 0.3837 & \pm 0.3046 & \pm 0.2148 \\
\hline
\end{tabular}

*:results by Wang [9]

**:this study-Eq (6)

The internal forces developed in the final tunnel lining, obtained from dynamic numerical analyses, are presented in Table 3 and in Figures 6 and 7. Closed-form, pseudo-static results for both the full-slip and no-slip case are also provided in Table 3 and compared against the dynamic time histories in Figures 6 and 7. To facilitate comparison, the axial hoop forces and bending moments are normalized as $T_{\max } /(\sigma \cdot r)$ and $M_{\max } /\left(\sigma \cdot r^{2}\right)$ respectively [7], with $\sigma_{y y}$ being the maximum seismic normal stress for the P-waves, or the maximum seismic shear stress $T_{x y}$ for the case of S- waves. 

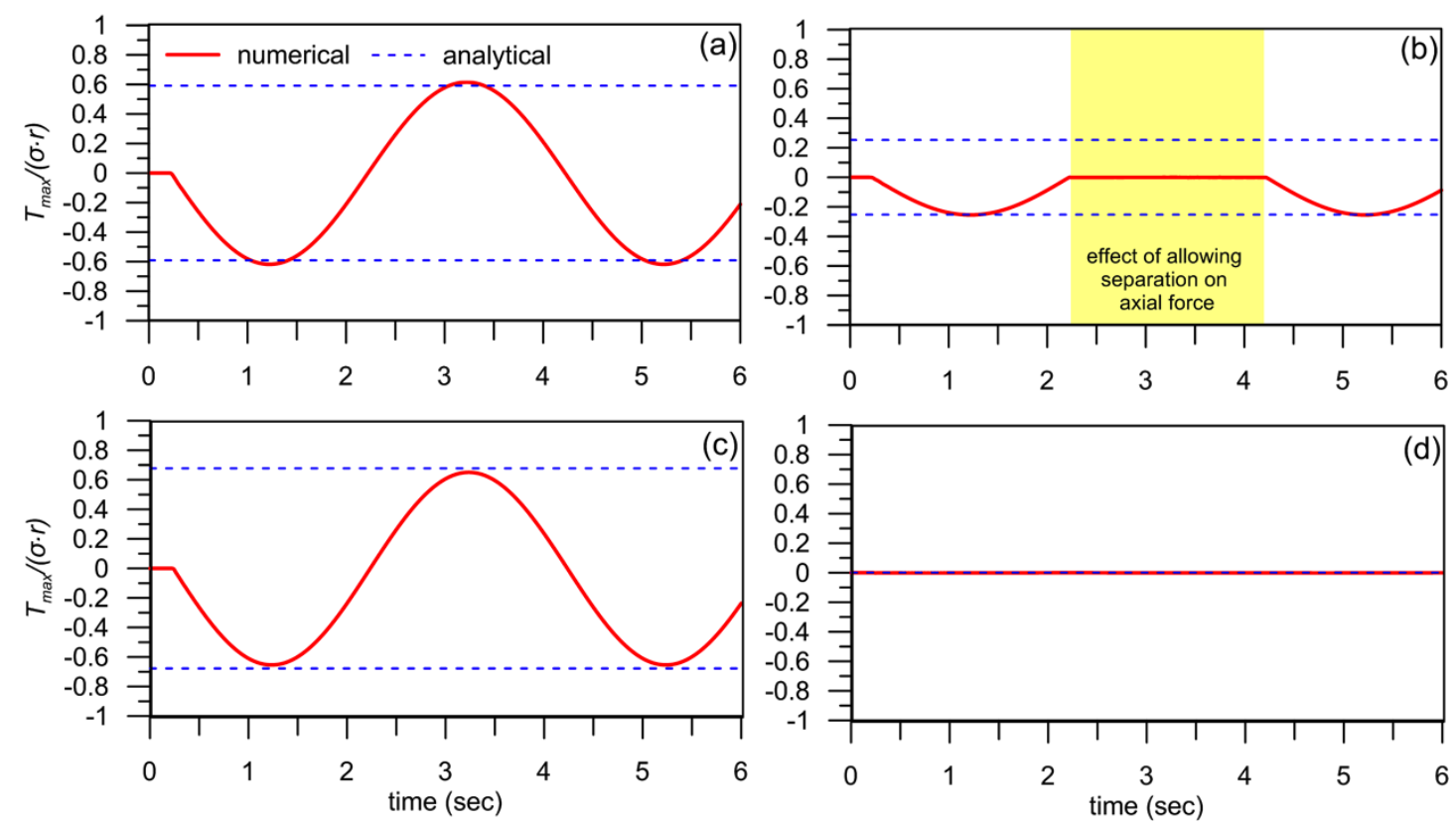

Figure 6. Normalized maximum liner axial force time histories compared against analytical results for (a) P-wave under no-slip conditions, (b) P-wave under full-slip conditions, (c) S-wave under no-slip conditions, and (d) S-wave under full-slip conditions. Negative values are compressive.
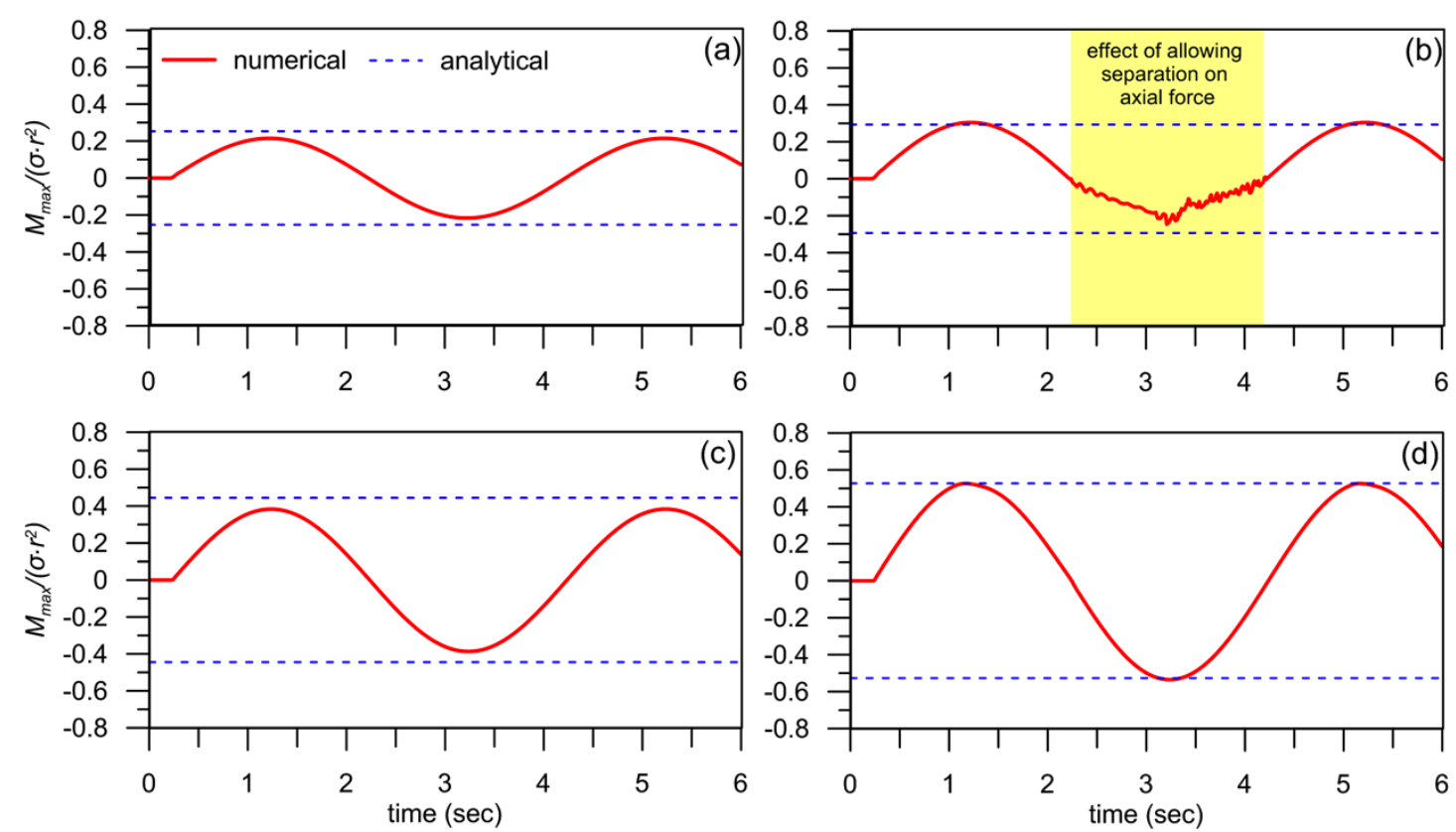

Figure 7. Normalized maximum liner bending moment time histories compared against analytical results for (a) P-wave under no-slip conditions, (b) P-wave under full-slip conditions, (c) S-wave under no-slip conditions, and (d) S-wave under full-slip conditions.

As indicated in Table 3 and Figures 6 and 7, there is a fair match between the numerical and analytical predictions of the internal forces, for all four conditions considered. Similar findings for the S-wave case were reported by Wang [9] and 
Hashash et al. [14] for the no-slip interface condition, and Sedarat et al. [21] for the full-slip condition. As expected, for a relatively flexible tunnel lining, the axial forces due to S-wave propagation under full-slip conditions are negligible. When separation under tensile stress is allowed at the rock mass-structure interface, no tensile forces develop whatsoever in the liner. The latter finding is also in line with the results of the quasi-static numerical analyses presented by Sedarat et al. [21] for S-waves. However, this is not the case for the axial hoop forces due to P-wave propagation, where full-slip and no-slip conditions result in comparable axial thrust values. Finally, the effect of separation on the bending moments is of secondary importance, although full-slip conditions consistently lead to the development of higher bending moments in the liner.

\section{Summary and conclusions}

A new set of analytical expressions is proposed in this study to quantify the effect of compressional P-seismic wave propagation on the final tunnel lining. It is shown that P-waves impinging at the rock mass-liner interface can result in significant axial hoop forces, even under full-slip conditions, which are considerably higher than the corresponding forces due to shear S-waves of similar, or even lower amplitude. This finding is of practical importance for tunnels that are constructed near slopes of irregular topography, or bored through heterogeneous rock mass conditions. The effect of the contact interface conditions examined (full-slip and no-slip), although important, is not as significant as for the S-wave case, where the full-slip conditions generates trivial axial forces in the lining.

The numerical results suggest that separation under tensile normal stress at the rock mass-liner interface eliminates the development of tensile hoop forces in the lining. This is a practical conclusion that is of paramount importance in the design of unreinforced concrete tunnel linings. Similar findings were reported by Sedarat et al. 
[21] for the S-wave case. In both P- and S-wave propagation, the tensile axial hoop forces should be neglected.

The proposed closed-form solution can be applied to assess the effect of P-waves, at least for preliminary estimates of the tunnel response, or as a guideline for validating case-specific numerical models. As the full-slip assumption describes the actual contact interface behaviour better $[21,27]$, the new expressions for calculating the internal forces in the lining can be used.

Finally, quasi-static numerical analyses of a tunnel seismic response do not offer much useful information, as they fail to simulate wave reflection/refraction effects. Indeed, it is clear that more elaborate dynamic numerical analyses are necessary for the design of actual tunnels under field conditions.

\section{References}

[1] A.F.T.E.S. Recommendations in respect of the use of plain concrete in tunnels. Tunnels et Ouvrages Souterrains, No 158, Mars/Avril; 2000.

[2] Deutsche Norm DIN 1045-1:2001. Plain, reinforced and prestressed concrete structures. Part 1: Design and construction. DIN Deutsches Institut für Normung e. V., Berlin, Germany.

[3] European Standard EN-1992-1-1. Eurocode 2:Design of concrete structuresPart 1: General rules and rules for buildings; 2003.

[4] Power MS, Rosidi D, Kaneshiro JY. Seismic vulnerability of tunnels and underground structures revisited. In: Proc. North American Tunnelling '98, Balkema; 1998, p.243-250.

[5] Sharma S, Judd, WR. Underground opening damage from earthquakes. Engineering Geology 1991; 30: 263-276.

[6] Ashford SA, Kawamata Y. Performance of transportation systems during the 2004 Niigata Ken Chuetsu, Japan, Earthquake. Earthquake Spectra 2006; 22(S1):111-132.

[7] Yashiro K, Kojima Y, Shimizu M. Historical earthquake damage to tunnels in Japan and case studies of railway tunnels in the 2004 Niigataken-Chuetsu earthquake. Quarterly Report of RTRI 2007;48-3:136-141.

[8] Sinozuka M. The Hanshin-Awaji earthquake of January 17, 1995: performance of lifelines. NCEER-95-0015; 1995.

[9] Wang JN. Seismic design of tunnels-A simple state-of-the-art design approach. Parsons Brinckerhoff, New York, Monograph 7; 1993.

[10] Penzien J. Seismically induced racking of tunnel linings. Earthquake Engineering and Structural Dynamics 2000; 29:683-691. 
[11] Penzien J, Wu CL. Stresses in linings of bored tunnels. Earthquake Engineering and Structural Dynamics 1998;27:283-300.

[12] Park K-H, Tantayopin K, Tontavanich B, Owatsiriwong A. Analytical solution for seismic-induced ovaling of circular tunnel lining under no-slip interface conditions: A revisit. Tunneling and Underground Space Technology 2009;24: 231-235.

[13] Hashash YMA, Hook JJ, Schmidt B, Yao JI-C. Seismic design and analysis of underground structures. Tunneling and Underground Space Technology 2001; 16:247-293.

[14] Hashash YMA, Park D, Yao JI-C. Ovaling deformations of circular tunnels under seismic loading, an update on seismic design and analysis of underground structures. Tunneling and Underground Space Technology 2005; 20:435-441.

[15] Hoeg K. Stresses against underground structural cylinders. Journal of Soil Mechanics and Foundation Division ASCE 1968;94:SM4.

[16] Peck RB, Hendron AJ, Mohraz B. State of the art in soft ground tunneling. In: The Proceedings of the Rapid Excavation and tunneling Conference. American Institute of Mining, Metallurgical and Petroleum Engineers, New York, NY;1972, p. 259-286.

[17] Geli L, Bard P-Y, Jullien B. The effect of topography on earthquake ground motion: A review of new results. Bulletin of the Seismological Society of America 1998;78-1:42-63.

[18] Paolucci R. Amplification of earthquake ground motion by steep topographic irregularities. Earthquake Engineering and Structural Dynamics 2002;31-10: 18311853.

[19] Bouckovalas GD, Kouretzis GP. Review of soil and topography effects in the September 7, 1999 Athens (Greece) earthquake. Proc. of $4^{\text {th }}$ Int. Conf. on Recent Advances in Geotechnical Earthquake Engineering and Soil Dynamics, San Diego California; 2001.

[20] Bouckovalas GD, Papadimitriou AG. Numerical evaluation of slope topography effects on seismic ground motion. Soil Dynamics and Earthquake Engineering 2005;25(7-10): 547-558.

[21] Sedarat H, Kozak A, Hashash YMA, Shamsabadi A, Krimotat A. Contact interface in seismic analysis of circular tunnels. Tunneling and Underground Space Technology 2009;24:482-490.

[22] Ranken RE, Ghaboussi J, Hendron AJ. Analysis of ground-liner interaction for tunnels. Report No. UMTA-IL-06-0043-78-3, U.S. Department of Transportation, Washington DC;1978.

[23] F.H.W.A. Technical manual for design and construction of road tunnels-Civil elements. U.S. Department of Transportation, Federal Highway Administration. Publication No. FHWA-NHI-10-034, December; 2009.

[24] Hendron AJ Jr, Fernandez G. Dynamic and static considerations for underground chambers. In: Seismic design of embankments and caverns. New York;1983, p. 157-97.

[25] O'Rourke MJ, Liu X. Response of buried pipelines subject to earthquake effects. Monograph series MCEER; 1999.

[26] European Standard EN-1998-1. Eurocode 8:Design of structures for earthquake resistance-Part 1: General rules, seismic actions and rules for buildings; 2003. 
[27] Kouretzis GP, Sloan SW, Carter JP. Effect of interface friction on tunnel liner internal forces due to seismic S- and P- wave propagation. Soil Dynamics and Earthquake Engineering 2013;46:41-51.

[28] Abaqus/Standard - User's Manual - version 6.11. Dassault Systemes Simulia Corp.

[29] N.C.H.R.P. National Cooperative Highway Research Program. Seismic analysis and design of retaining walls, buried structures, slopes and embankments. Transportation Research Board Report 611, Washington DC; 2008. 


\section{Nomenclature}

$M_{\max }$ maximum bending moment in the lining

$T_{\max } \quad$ maximum axial force in the lining

e eccentricity

$E_{m} \quad$ elasticity modulus of the rock mass

$K_{m} \quad$ bulk modulus of the rock mass

$M_{m} \quad$ constrained modulus of the rock mass

$E_{l} \quad$ elasticity modulus of the tunnel liner

$v_{m} \quad$ Poisson ratio of the rock mass

$v_{l} \quad$ Poisson ratio of the tunnel liner

$r \quad$ tunnel external radius

d tunnel external diameter

$t \quad$ tunnel liner thickness

I moment of inertia of the tunnel liner

$V_{\max } \quad$ maximum free-field shear strain

$G_{m} \quad$ shear modulus of the rock mass

$\rho_{m} \quad$ density of the rock mass

$v_{S} \quad$ peak ground velocity due to S-wave propagation

$V_{P} \quad$ peak ground velocity due to $P$-wave propagation

$F \quad$ flexibility ratio

C compressibility ratio

$\gamma_{m} \quad$ unit weight of the rock mass

$h \quad$ tunnel overburden

$K_{o} \quad$ in-situ stress ratio

$\sigma_{\max } \quad$ maximum free-field normal stress

$I_{\max } \quad$ maximum free-field shear stress

$C_{S} \quad$ shear wave velocity

$C_{P} \quad$ compressional wave velocity 
7. Appendix A - Analytical expressions of circular tunnel internal forces under geostatic stress field (after Ranken et al. [19], [29])

\begin{tabular}{|c|c|c|c|c|c|}
\hline \multirow{3}{*}{ 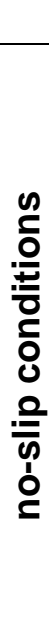 } & \multirow[b]{2}{*}{$\begin{array}{l}\frac{5}{3} \\
\frac{0}{0} \\
\frac{0}{2} \\
\frac{c}{2} \\
\frac{1}{2}\end{array}$} & \multicolumn{2}{|c|}{ Axial force, $T$} & \multicolumn{2}{|r|}{ Bending moment, M } \\
\hline & & $\left(\frac{\gamma_{m} h d}{4}\right)$ & {$\left[\begin{array}{l}\left(1+K_{0}\right)\left(1-L_{n}\right) \\
-\left(1-K_{0}\right)\left(1+J_{n}\right.\end{array}\right.$} & $\frac{\gamma_{m} h\left(\frac{d}{2}\right)^{2}}{2}$ & {$\left[\begin{array}{l}\left(1+K_{o}\right)\left(1-2 \nu_{m}\right)\left(\frac{C}{6 F}\right)\left(1-L_{n}\right) \\
-\frac{\left(1-K_{o}\right)}{2}\left(1-J_{n}-2 N_{n}\right)\end{array}\right.$} \\
\hline & 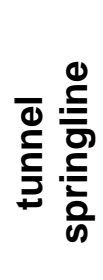 & $\left(\frac{\gamma_{m} h d}{4}\right)$ & {$\left[\begin{array}{l}\left(1+K_{o}\right)\left(1-L_{n}\right) \\
+\left(1-K_{o}\right)\left(1+J_{n}\right.\end{array}\right.$} & $\frac{\gamma_{m} h\left(\frac{d}{2}\right)^{2}}{2}$ & {$\left[\begin{array}{l}\left(1+K_{o}\right)\left(1-2 \nu_{m}\right)\left(\frac{C}{6 F}\right)\left(1-L_{n}\right) \\
+\frac{\left(1-K_{o}\right)}{2}\left(1-J_{n}-2 N_{n}\right)\end{array}\right.$} \\
\hline$\frac{\text { ? }}{\frac{0}{0}}$ & $\begin{array}{l}\frac{5}{3} \\
\frac{0}{d} \\
\frac{d}{d} \\
\frac{1}{5} \\
\frac{1}{2}\end{array}$ & $\left(\frac{\gamma_{m} h d}{4}\right)$ & {$\left[\begin{array}{l}\left(1+K_{0}\right)\left(1-L_{f}\right) \\
-\left(1-K_{0}\right)\left(1-J_{f}\right)\end{array}\right.$} & $\frac{\gamma_{m} h\left(\frac{d}{2}\right)^{2}}{2}$ & $\begin{array}{l}\left(1+K_{0}\right)\left(1-2 \nu_{m}\right)\left(\frac{C}{6 F}\right)\left(1-L_{f}\right) \\
-\left(1-K_{o}\right)\left(1-J_{n}\right)\end{array}$ \\
\hline $\begin{array}{l}\frac{0}{2} \\
\frac{2}{\bar{c}} \\
\frac{1}{\overline{2}}\end{array}$ & 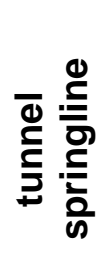 & $\left(\frac{\gamma_{m} h d}{4}\right)$ & $\begin{array}{l}\left(1+K_{o}\right)\left(1-L_{f}\right) \\
+\left(1-K_{o}\right)\left(1-J_{f}\right)\end{array}$ & $\frac{\gamma_{m} h\left(\frac{d}{2}\right)^{2}}{2}$ & $\begin{array}{l}\left(1+K_{o}\right)\left(1-2 \nu_{m}\right)\left(\frac{C}{6 F}\right)\left(1-L_{n}\right) \\
+\left(1-K_{o}\right)\left(1-J_{f}\right)\end{array}$ \\
\hline
\end{tabular}

where:

\begin{tabular}{|l|}
\hline$L_{n}=\left(1-2 \nu_{m}\right)(C-1) /\left[1+\left(1-2 \nu_{m}\right) C\right]$ \\
$J_{n}=\frac{\left(1-2 \nu_{m}\right)(1-C) F-0.5\left(1-2 \nu_{m}\right)^{2} C+2}{\left[\left(3-2 \nu_{m}\right)+\left(1-2 \nu_{m}\right) C\right] F+\left[0.5\left(5-6 \nu_{m}\right)\left(1-2 \nu_{m}\right) C+\left(6-8 \nu_{m}\right)\right.}$ \\
$N_{n}=\frac{\left[1+\left(1-2 \nu_{m}\right) C\right] F-\left[0.5\left(1-2 \nu_{m}\right) C\right]-2}{\left[\left(3-2 \nu_{m}\right)+\left(1-2 \nu_{m}\right) C\right] F+\left[0.5\left(5-6 \nu_{m}\right)\right]\left(1-2 \nu_{m}\right) C+\left(6-8 \nu_{m}\right)}$ \\
\hline$L_{f}=\left(1-2 \nu_{m}\right)(C-1) /\left[1+\left(1-2 \nu_{m}\right) C\right]$ \\
\hline$J_{f}=\left[2 F+\left(1-2 \nu_{m}\right) /\left[2 F+\left(5-6 \nu_{m}\right)\right]\right.$ \\
\hline$N_{f}=[2 F-1] /\left[2 F+\left(5-6 \nu_{m}\right)\right]$ \\
\hline
\end{tabular}

